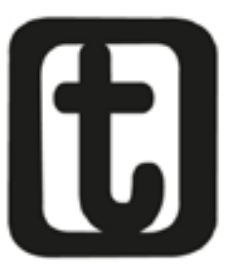

\title{
OS DESAFIOS DA FORMAÇÃO PROFISSIONAL NA GESTÃO 2005-2006
}

\author{
The challenges of professional training in management \\ 2005-2006
}

\section{Ana Elizabete Mota'}

A trajetória da Associação Brasileira de Ensino e Pesquisa em Serviço Social (Abepss), entidade que completa 65 anos de existência, inegavelmente se confunde com a própria história da educação superior e da profissionalização do Serviço Social brasileiro. Seu protagonismo político, a partir dos anos finais da década de setenta e durante os anos 80 , foi fundamental para que o Serviço Social brasileiro assumisse uma direção intelectual crítica, articulando coletivamente um novo projeto de formação profissional. Referimo-nos àqueles anos para ressaltar a conjuntura brasileira dos finais dos anos 70, então marcada pelo esgotamento da ditadura militar e pela emergência de movimentos sociais que, prolongando-se pela década de 1980, exigiam a democratização da sociedade e a constituição de novos direitos civis, políticos e sociais.

Na passagem dos anos 90, sob o fogo cruzado da contrarreforma do Estado burguês, também a Abepss assume seu papel de dirigen-

\footnotetext{
1 Professora Titular da Universidade Federal de Pernambuco (UFPE) e ex-presidente da Abepss na gestão 2005-2006. E-mail: <bmota@elogica.com.br>.
} 
te no ambiente da formação profissional, desenvolvendo ações de natureza organizativa e formativa de modo a construir as novas diretrizes curriculares para o Curso de Serviço Social, num processo de embate e resistência às grandes linhas definidas pela Lei de Diretrizes e Bases da Educação (LDB) e implementadas no governo Fernando Henrique Cardoso (FHC). Dentre elas, destacam-se: a expansão do ensino privado superior, a liquidação da organicidade entre ensino/pesquisa/extensão, a transformação das instituições em organizações de ensino superior, a subordinação das universidades às demandas do mercado, a noção de autonomia universitária adstrita ao âmbito financeiro e as inflexões deste processo na lógica da administração universitária.

Marcada por um ambiente adverso ao proposto pelas Diretrizes Curriculares formuladas pela Abepss, a formação profissional e a educação superior, às quais se inclui a do Serviço Social, foram seriamente afetadas pelo desenvolvimento daquele processo (ainda inconcluso) cujo fim último é adequar a educação superior às necessidades do capital financeiro e especulativo que, dentre outros aspectos, transforma políticas e serviços sociais em campos de investimento, mercantilização e espaço intermediador da acumulação capitalista.

Mais complexa do que nos anos 90, a política de educação superior formulada e implementada no governo Lula da Silva, na primeira década dos anos 2000, adota uma pedagogia que tem a capacidade de obter consensos junto à sociedade, posto que era permeada de apelos populistas e de usos transformistas de conceitos e reivindicações que foram tecidas no campo da esquerda combativa e dos trabalhadores organizados.

Tratou-se, na verdade, de atender algumas demandas tecidas no campo da esquerda, mas destituindo-as do seu significado original, de que são exemplos: o direito à educação, transformado em acesso aos serviços educacionais através do mercado; a ampliação de vagas atendida através da expansão de instituições privadas mercantis e do ensino a distância; a qualidade do ensino que passa a ser tratada como uma questão de eficiência e eficácia; a relação 
entre público e privado como esferas complementares. Além disso, procuraram suprimir as tensões e os projetos de uma formação superior laica, pública e socialmente referenciada através do marketing social, via política de cotas, financiamento das mensalidades do ensino privado e da abertura desmedida de novos cursos, através do Reuni e da interiorização de novas Instituições de Ensino Superior (IES). Foi neste contexto que assumimos a direção nacional da Abepss, no biênio 2005-20062.

Esta conjuntura nacional, cuja direção assumida pelo Governo Lula deu continuidade e/ou não alterou algumas das reformas de corte neoliberal, iniciadas pelo governo Fernando Henrique, exigiu do coletivo profissional uma postura de resistência às reformas como a da Previdência Social e a da Educação Superior; preservando a sua autonomia organizativa, sem negar os avanços existentes, mas postando-se criticamente diante das contradições do governo. Dentre elas, destacam-se a promessa de um governo democrático e popular e a prática de uma política econômica que favoreceu ao grande capital e primou por tratar as desigualdades sociais como uma questão de pobreza, permitindo que a educação fosse tratada como negócio, inclusive admitindo a existência de franquias comerciais de instituições do sul e sudeste nas demais regiões do país.

Neste contexto, também a Abepss transforma-se numa entidade cuja direção política é campo de disputa por uma direção social estratégica, tendo em vista que, para atingir suas finalidades, é requerida a mediação da política, da teoria e da ideologia. Em face destas considerações, a gestão 2005-2006 definiu os seguintes pontos como centrais na sua gestão: a defesa e aprofundamento das diretrizes curriculares da Abepss como meio garantidor da di-

\footnotetext{
${ }^{2}$ Compuseram a direção da Abepss os seguintes docentes e estudantes: na Executiva Nacional: Ana Elizabete Simões da Mota Fernandes (Presidente), Maria Alexandra Monteiro Mustafá (Secretária), Roberta Salazar Uchoa (tesoureira), Maria Marieta dos Santos Koike (Coordenadora Nacional de Graduação), Marina Maciel Abreu (Coordenadora Nacional de Pós-Graduação), Edístia Maria Abath (suplente) e Josefa Batista Lopes (suplente e Coordenação de articulação internacional); nas Vices-presidências Regionais: (a) Região Norte: Maria Antonia Cardoso Nascimento; (b) Região Nordeste: Maria da Conceição Pio; (c) Região Leste: Marilene Schelgshorn dos Santos Sansão; (d) Região Centro-Oeste: Patrícia Cristina Pinheiro de Almeida; (e) Região Sul 1: Edaléa Maria Ribeiro; e (f) Região Sul 2: Maria Beatriz Costa Abramides. Como representantes da Graduação: as discentes Daniela Moller (Titular) e Ymira da Silva (Suplente); Como representantes da Pós-Graduação: Naíres Raimunda Gomes Farias (Titular) e Cézar Henrique Miranda Coelho Maranhão (Suplente).
} 
reção e qualidade da formação profissional dos assistentes sociais, a articulação com as entidades da categoria Conselho Federal de Serviço Social/Conselhos Regionais de Serviço Social (CFESS/Cress), Executiva Nacional dos Estudantes de Serviço Social (Enesso) e APG no engajamento nas lutas sociais e em defesa das políticas públicas e dos direitos sociais, o fortalecimento da Abepss junto às Pós-Graduaçõos em Serviço Social e a articulação latino-americana do Serviço Social.

Referendada no protagonismo de seis décadas de atuação, a direção nacional e as vices-presidências regionais foram consensuais no que se refere ao entendimento de que a Abepss deveria estar preparada para enfrentar os desafios daquela conjuntura, fortalecendo-se política, financeira e administrativamente e construindo mecanismos e estratégias que dotassem a entidade da capacidade de ser "[...] um aparelho privado de hegemonia [...]", constituindo-se na principal interlocutora no campo do ensino e da pesquisa em Serviço Social.

Foram definidos os seguintes princípios e estratégias que balizaram o mandato daquela gestão:

Gestão da Abepss - Seu modelo de gestão privilegiou a democracia interna, a descentralização das atividades (incorporando as vice-regionais em todas as deliberações) através da formação de Grupos de Trabalhos temáticos e operativos, além da ampliação das filiações das IES e da comunicação entre a direção e as unidades de ensino. Foram formados os seguintes Grupos de Trabalhos: 1) Curso a distância em parceria com CFESS; 2) Pesquisa da Implementação das Diretrizes curriculares nas IES; 3) Pesquisa e Pós-Graduação; 4) Publicações; e 5) Relações Internacionais. Todos compostos por membros da Executiva Nacional, das regionais e convidados.

Relações político-institucionais - Pautada na articulação, no engajamento, no acompanhamento e na participação das ações institucionais afetas à formação profissional na quais se incluem instituições governamentais como Ministério da Educação (MEC), Conselho Nacional de Desenvolvimento Científico e Tecnológico CNPq, Instituto Nacional de Estudos e Pesquisas Educacionais 
(Inep), Coordenação de Aperfeiçoamento de Pessoal de Nível Superior (Capes) e de projetos específicos como o Educação para o SUS (Educar-SUS) e a avaliação do ensino superior.

Ensino de graduação - Desenvolvimento de atividades permanentes e eventuais de modo a atingir as seguintes metas: 1) Realização de uma pesquisa para identificar o estado da arte da implementação das Diretrizes Curriculares e suas inflexões nos currículos e projetos pedagógicos das IES; 2) Socialização dos dados da pesquisa e encaminhamento de discussões para aprofundamento de questões relativas às diretrizes e seus ajustes nos currículos; 3 ) Dar prosseguimento às discussões para elaboração da Política Nacional de Estágio na área do Serviço Social; 4) Realização de atividades em conjunto com a Pós-Graduação, de modo a desenvolver estudos e pesquisas que contemplem temas e questões das Diretrizes Curriculares; 5) Enraizar as discussões sobre a formação profissional junto às IES públicas, privadas, comunitárias e confessionais; e 6) Empreender esforços no sentido de acompanhar e atender às demandas dos novos cursos de Serviço Social.

Pesquisa e pós-graduação - Priorização da ampliação e consolidação do papel da Abepss na qualidade de associação científica junto aos Programas de Pós-Graduação em Serviço Social e órgãos de fomento. Advogava-se uma permanente articulação entre graduação e pós-graduação, respeitadas as especificidades de ambos os níveis da formação profissional. Foram estabelecidas como metas: 1) Submeter à aprovação o projeto de criação de uma revista nacional da pós-graduação em Serviço Social, envolvendo todos os programas da área; 2) Realizar um encontro nacional de Pós-Graduação em Serviço Social; 3) Encaminhar as deliberações e recomendações do IX Encontro Nacional de Pesquisadores em Serviço Social (Enpess) sobre a pesquisa em Serviço Social; e 4) Elaboração de projeto editorial e constituição de conselho editorial para a Revista Temporalis.

Articulação internacional - Pautada pelo propósito de consolidar as relações internacionais da Abepss, sobretudo na América Latina e Caribe no âmbito da pesquisa e da formação profissional. Priori- 
tariamente estaria voltada para as possibilidades de reconstrução da Associação Latino Americana de Escolas de Trabalho Social (Alaets), mediante encaminhamento dos compromissos assumidos coletivamente pela Abepss, durante a gestão anterior, dentre os quais, apoiar a atual Junta Diretiva e realizar um Seminário Latino-americano no Brasil.

O conjunto das iniciativas aqui expostas revelam o compromisso da Executiva Nacional e das Vice-presidências com as Diretrizes e os eixos programáticos da gestão 2005-2006, cuja implementação dependeu das condições objetivas existentes e da capacidade de a Abepss mobilizar e articular as IES nas diversas regiões em torno da direção social estratégica que informa as Diretrizes Curriculares por ela elaboradas.

\section{PARA NÃO DIZER QUE NÃO FALAMOS DE FLORES}

Como exposto anteriormente, muitos foram os desafios enfrentados pela Gestão 2005-2006. Assim, na falta de uma consulta aos que a compuseram para escrever este pequeno informe, vali-me de documentos pessoais para expor uma síntese dos aspectos que considero fundamentais. Não tenho dúvidas em afirmar que merecem destaques algumas iniciativas dessa gestão, pelo peso teórico, ideopolítico e institucional que tiveram e têm até hoje na Abepss:

A mobilização nacional em torno das Diretrizes Curriculares antes e após a conclusão da pesquisa nacional, envolvendo diretamente 102 IES e inúmeros estudantes e docentes através das Oficinas Nacionais Descentralizadas, ocorridas em todas as regionais da Abepss. A realização da pesquisa foi precedida da apresentação de um vídeo problematizando algumas questões e sucedida pelo envio de questionários a serem preenchidos pelas coordenações dos cursos de graduação. Posteriormente, com os dados já tabulados, foram feitas apresentações e discussões sobre os dados de cada uma das regiões. Embora não tenha havido consenso sobre a abordagem ao objeto da pesquisa, e por vezes até críticas e boicotes, consideramos que o processo foi democrático, respeitoso 
e bem-sucedido, deixando um legado dessa gestão para a área do Serviço Social e publicado na Revista Temporalis de $n^{\circ} 14$, em 2007. O relatório da pesquisa é o único documento que dispõe a Abepss e as Instituições de Ensino Superior para avaliarem os avanços e as dificuldades de implementação das Diretrizes e planejar meios de aprofundamento e discussão sobre o tema;

1. A mobilização nacional em torno da rearticulação do Serviço Social latino-americano e caribenho, culminando com a refundação da Alaets mediante a criação da Associação Latino-Americana de Ensino e Pesquisa em Serviço Social / Asociación Latinoamericana de Enseñanza e Investigación en Trabajo Social - Nome da entidade em espanhol (Alaeits) - ocasião em que acumulamos a presidência da Abepss e a da nova Entidade, dando, assim, visibilidade ao Serviço Social brasileiro que, naquela ocasião, foi o único país a apresentar um documento programático, servindo de base para a estruturação e funcionamento da Alaeits;

2. O estreitamento das relações da Abepss com as Pós-Graduações, seja através de reuniões e elaboração de agendas, seja durante a elaboração de nova árvore do conhecimento, com a apresentação de uma proposta para as áreas e subáreas do Serviço Social no CNPq. Ainda neste aspecto, destaco a criação do Seminário Nacional da Pós-Graduação, em 2005 - um fórum para discussões específicas dos Programas e das representações da área nas Agencias de fomento. Igualmente importante é salientar a inauguração de um novo formato para o Enpess, com a criação de Oficinas de Iniciação Científicas, de Projetos de teses e dissertações, encontros de redes e grupos de pesquisa e de Editores. Destacamos, ainda, a elaboração do projeto editorial da Revista Temporalis, assim como a criação do seu Conselho Editorial;

3. Realização do Projeto Fórum Nacional de Educação das Profissões da Área da Saúde/Ministério de Saúde/Organização Panamericana de Saúde (FNEPAS/MS/OPAS), idealizado na gestão da Professora Jussara Maria Rosa Mendes e apresentado e im- 
plementado em 2005, permitindo realização de Seminários regionais sobre a Interface do Serviço Social com a Saúde e a publicação de uma coletânea, cujos direitos autorais pertencem a Abepss, atualmente na sua terceira edição. Esse projeto foi responsável pela obtenção de recursos que permitiram tratar a formação profissional em sua totalidade, inclusive, subsidiando os gastos da pesquisa das Diretrizes;

4. Criação e profissionalização do Boletim Abepss mediante a contratação de uma assessoria de comunicação que, além do informativo mensal, elaborou um novo site da Abepss, inclusive realizando a recuperação do domínio na internet da referida associação, a saber: Disponível: <http://www.abepss.org.br>.

5. Reforma dos Estatutos da Abepss, com a criação da Coordenação de Relações Internacionais, a normatização da participação discente de graduação e pós-graduação, dentre outros aspectos relevantes.

Em suma, temos a convicção da importância dessa gestão para o avanço da formação profissional, da pesquisa e da representatividade da Abepss junto às Pós-Graduações da área do Serviço Social, o que comprova o compromisso da Direção Nacional e Regional da Abepss em 2005-2006 com o pluralismo, a democracia interna e o horizonte político-estratégico e teórico que definem a direção social da nossa profissão na realidade brasileira. 